\title{
Crop Load and Time of Thinning Interact to Affect Fruit Quality in Sweet Cherry
}

\author{
Sally A Bound ${ }^{1}$, Dugald C Close ${ }^{1}$, Audrey G Quentin ${ }^{1,2}$, Penelope F Measham ${ }^{1} \&$ Matthew D Whiting ${ }^{3}$ \\ ${ }^{1}$ Perennial Horticulture Centre, Tasmanian Institute of Agriculture, University of Tasmania, Hobart 7001, \\ Australia \\ ${ }^{2}$ CSIRO Ecosystem Sciences, Private Bag 12, Hobart 7001, Australia \\ ${ }^{3}$ Washington State University, 24106 N. Bunn Road, Prosser, WA, USA \\ Correspondence: Dugald C Close, Perennial Horticulture Centre, Tasmanian Institute of Agriculture, University \\ of Tasmania, Hobart 7001, Australia. E-mail: Dugald.Close@utas.edu.au
}

Received: May 15, 2013 Accepted: June 6, 2013 Online Published: July 15, 2013

doi:10.5539/jas.v5n8p216 URL: http://dx.doi.org/10.5539/jas.v5n8p216

\begin{abstract}
Balanced crop load is key to the production of export-quality cherries. We investigated the level and timing of crop load regulation on fruit quality. Additionally we sought to investigate possible correlation between firmness estimated by compression test or flesh penetrability. Fruit diameter was similar between 1 and 2 bud/spur treatments but was significantly lower in the 4 bud/spur treatment at all thinning times in 'Van' in the 2010/11 season. In contrast 'Sweetheart' fruit diameter was only decreased at 6 and 8 WAFB in the 4 bud/spur treatment in 2010/11. This decrease in 'Sweetheart' was associated with significantly higher soluble solids and starch reserves in leaves, stem, trunk and roots 2-weeks post-harvest in trees thinned at dormancy, relative to trees thinned 8 WAFB. Fruit flesh firmness significantly increased with decreased crop load irrespective of time of thinning in 'Van' in 2010/11. In contrast flesh firmness was significantly higher in the 1 bud/spur treatment and similar between other treatments in 'Sweetheart' in 2010/11. In 2011/12 flesh firmness, soluble solids and colour significantly increased whilst fruit weight and TA significantly decreased 28 days post-harvest relative to at-harvest values. We found strong correlation between values obtained with the FirmTech II and the Guss fruit texture analyser. Sweet cherry fruit quality is optimised through attaining crop load of approximately 10 fruit per $\mathrm{cm}^{2}$ of limb cross-sectional area through thinning at dormancy or full bloom.
\end{abstract}

Keywords: carbohydrate, cherry, crop load regulation, post-harvest, thinning

\section{Introduction}

Sweet cherry is a high value crop where quality can attract significant premiums. High grower returns are particularly important for economic sustainability in countries with high production costs. Due to premium returns in export markets, sweet cherry fruit from Australia are shipped overseas. To maximize returns, and ensure the retention of fruit quality, in overseas markets, growers must deliver large, firm fruit with high sugar levels. Horticulturally, crop load regulation is a key to producing fruit with desired quality attributes (Link 2000) as over-cropped trees produce small, soft fruit due to limited carbohydrate and nutrient supply (Proebsting \& Mills, 1981; Whiting \& Lang, 2004).

Regulation of crop load can be achieved by several methods: hand-thinning, chemical thinning, mechanical thinning, artificial spur extinction (removal of complete spur from the branch; Ayala \& Andrade, 2009) or bud thinning. Hand-thinning is expensive and time consuming (Childers, 1983). Chemical blossom thinning is becoming more widespread, however there are limited options available and many Australian growers are wary of thinning during the bloom period because of the potential risk of over-thinning from subsequent frost damage. The caustic blossom thinner ammonium thiosulfate (ATS) is gaining in popularity, but timing of application is critical and can be difficult in practice in addition to uncertainty regarding the efficacy of thinning (Bound \& Jones, 2004; Whiting et al., 2006). There is conflicting evidence on the impact of spur extinction and bud thinning on fruit quality and yield. Whiting and Lang (2004) reported a reduction in yield and increase in fruit size, firmness and sugar content in the 'Bing' variety on dwarfing Gisela 5 rootstock trained to a free-standing, multiple leader open-centre system, however Ayala and Andrade (2009) saw no response to spur thinning in 'Lapins' on the 
vigorous Mazzard F-12/1 rootstock trained to a central leader system. These authors speculated that the lack of response in Lapins/F-12/1 trees was due to fruit sink limitation or competition by vegetative sink. Einhorn et al. (2011) similarly reported no consistent quality responses to varying crop load on variety 'Sweetheart' on Mazzard F-12/1 and Measham et al. (2012) did not see any positive effect on fruit size or sugar accumulation after thinning in 'Regina' on Mazzard F-12/1 trained to a bush system. In a study of 'Lapins' on Maxima 14 rootstock, a positive effect on fruit size distribution following spur and bud thinning was observed, but without a reduction in yield (von Bennewitz et al., 2010), whereas yields were reduced on Sweetheart/F-12/1 after bud thinning such that the lowest crop loads returned the lowest returns to the grower in two consecutive seasons (Einhorn, 2011). Neilsen et al. (2007) make the observation that spur extinction results in permanent yield reductions, regardless of factors that may alter annual fruit set and additionally, that fruit firmness was only improved in lower cropping trees in one season. Measham et al. (2012) found no interaction or main effect of crop load intensity or timing of thinning on fruit firmness, but an interaction was evident on fruit size. The potential for crop load manipulation to positively influence fruit quality seems to be highly dependent on variety, rootstock and training system, as well as the level of crop load set.

A recently developed training system, known as the Kym-Green-Bush or KGB (Green, 2005), is comprised of $10-15$ branches arising from the main trunk which is headed in the first year at approximately $0.3 \mathrm{~m}$ from soil level. This system spreads vigour, provides superior internal rate of return compared to trellised Tatura or Sol-Axe systems (Close et al., in press), and relies on vegetative shoots only on the branches in addition to spur leaves for carbohydrate supply.

The objective of this study was to investigate the impacts of both crop density, and timing of crop load regulation by bud, flower or fruitlet thinning, on fruit quality of 'Van' and 'Sweetheart' on Mazzard F-12/1 rootstock trained to the KGB system. It was hypothesized that, given the lack of lateral shoots and therefore potentially low carbohydrate supply, fruit quality would be improved by thinning, and that crop load effects on fruit quality would be less apparent with later thinning due to lost carbohydrate resource invested in bloom and fruitlets. Additionally we sought to investigate possible correlation between firmness estimated by the FirmTech II or the GÜSS Fruit Texture Analyser.

\section{Methods}

Three trials were conducted on commercial orchards in southern Tasmania, Australia; at Plenty in the Derwent Valley $\left(42^{\circ} 71^{\prime} \mathrm{S}, 146^{\circ} 90^{\prime} \mathrm{E}\right)$, and Old Beach $\left(42^{\circ} 71^{\prime} \mathrm{S}, 146^{\circ} 90^{\prime} \mathrm{E}\right)$ over two consecutive seasons on mature, regular bearing 'Van' and 'Sweetheart' sweet cherry trees. Studies commenced in spring of 2010.

In the 2010/11 season, Trial 1 was conducted on 18-year-old 'Van' trees at Plenty and Trial 2 on nine-year-old 'Sweetheart' trees at Old Beach, near Hobart. The following season (2011/12) Trial 3 was conducted on nine-year-old 'Van' trees at Plenty.

These varieties were chosen to represent a commonly grown variety (Sweetheart) and a variety that generally has a higher crop load (Van) than other varieties.

All trees were on F-12/1 rootstocks and pruned to a KGB system. Row orientation in all trials was north-south, with a planting spacing of $4.8 \mathrm{~m} \times 2.5 \mathrm{~m}$ in Plenty, and $4.3 \times 2.0 \mathrm{~m}$ in Old Beach. Trees were subjected to standard orchard management with respect to irrigation, fertilisation and pest management.

\subsection{Experimental Design}

For each trial, trees were selected while dormant. Trees were blocked into groups depending on position within the row, and treatments were allocated at random to single tree plots within each block in a randomised complete block design. There were six replicates in Trials 1 and 2 and five replicates in Trial 3. In Trials 1 and 2 whole trees were used as the experimental unit whereas in Trial 3, two representative limbs were chosen on opposite sides of each tree.

\subsection{Treatments}

In all trials, buds/flowers or fruitlets were removed by hand (randomly selected given that we have previously tagged buds at dormancy and shown no effect on subsequent fruit quality) from whole trees to each crop load level at each thinning time as follows;

Trial 1: Crop load levels were achieved by thinning to 1,2 or 4 buds per spur at pre-bloom (approximately 28 days prior to full bloom), full-bloom (FB), 2 weeks after FB (WAFB), 4 WAFB, or 6 WAFB, giving a factorial arrangement of three crop loads $\mathrm{x}$ five thinning times. 
Trial 2: Crop load treatments were applied as in Trial 1 with an additional thinning time of 8 WAFB, giving a factorial arrangement of three crop loads $\mathrm{x}$ six thinning times.

Trial 3: Crop load levels were achieved by thinning to 2 or 4 buds per spur or left with the natural crop load at pre-bloom or $6 \mathrm{WAFB}$, giving a factorial arrangement of three crop loads $\mathrm{x}$ two thinning times.

\subsection{Sampling}

Harvest of experimental plots occurred in the mornings and was coordinated with commercial harvest in each orchard. All fruit from Trial 1 was picked into lugs by the grower (any rotten fruit was discarded by the pickers). Fruit for each tree was weighed in the field using a Salter Model 235 6s hanging scale suspended from a tripod and a subsample of at least 300 fruit taken for further analysis. Due to adverse weather conditions prior to harvest, Trial 2 was abandoned by the grower. The harvest regime was modified such that 2 limbs were harvested on each tree and total number and weight of fruit recorded separately for each limb. In Trial 3, all fruit was harvested from two marked limbs. Trunk (TCSA) and limb (LCSA) cross-sectional areas were calculated from circumference; measured at $4 \mathrm{~cm}$ above the graft union or at the base for trunk and limb respectively. Estimation of total yields in each trial was based either on total weight but not total fruit number (Trial 1) or as a multiple of fruit numbers per branch.

Harvested fruit from each trial was returned to the laboratory, weighed and sorted as either marketable, cracked or otherwise. From this data percent fruit cracked was calculated. For quality assessments a subsample of 25 blemish-free fruit was taken from each replicate of Trials 1 and 2, and 30 fruit from Trial 3.

Leaf (fully expanded on outer canopy) and wood samples (one sample from each aspect $=4$ samples per tree) for analysis of TSS and starch were taken two weeks after harvest from all trial trees thinned at dormancy and 8 WAFB in Trial 2 only. Two branches (east and west aspect) and the main trunk were sampled with a tree corer, whilst woody root material was sampled using a soil auger.

\subsection{Assessments (Quality)}

Fruit diameter was measured using digital vernier calipers and fruit weight was recorded using an AND digital balance (model GX-4000). Skin colour was assessed using the CTIFL (Centre Technique Interprofessionnel des Fruits et Légumes) color chart for cherries. A GÜSS Fruit Texture Analyser, model GS-20, fitted with a $2 \mathrm{~mm}$ penetrometer probe, operating at a penetration speed of $10 \mathrm{~mm} / \mathrm{second}$ and a penetration depth of $4 \mathrm{~mm}$, was used to measure flesh firmness (on pared flesh) and skin puncture force. In the second year, fruit firmness was also assessed using a Bio Works FirmTech II Fruit Firmness Tester, and stem retention was assessed by determining the stem pull force measured with a stand mounted Mark 10 force gauge. The incorporation of the FirmTech II into our fruit quality assessment allowed for investigation of correlation between values obtained with this and the GÜSS Fruit Texture Analyser.

Fruit from each replicate were then juiced collectively and 3 individual samples taken for measurement of total soluble solids (TSS), $\mathrm{pH}$ and titratable acidity (TA). TSS concentration ( $\left.{ }^{\circ} \mathrm{Brix}\right)$ was assessed with an Atago PR-1 digital refractometer, and juice $\mathrm{pH}$ and TA were determined using a Mettler Toledo G20 compact titrator.

In Trial 3, a further subsample of 30 fruit was taken from each replicate, placed into polyethylene bags which were then sealed to maintain the ambient environment at close to $100 \%$ relative humidity and then stored at $0^{\circ} \mathrm{C}$ with no atmospheric control. These fruit were assessed for post-harvest quality attributes as above after 28 days storage.

\subsection{Assessments (Carbohydrate Analysis)}

Soluble sugars were extracted from $100 \mathrm{mg}$ of dried, powdered leaf or wood tissue. For each sample, $3 \mathrm{~mL}$ of $80 \%(\mathrm{v} / \mathrm{v})$ ethanol was added and incubated at $60^{\circ} \mathrm{C}$. The samples were then centrifuged at $4000 \mathrm{~g}$ for $10 \mathrm{~min}$ at $8^{\circ} \mathrm{C}$. The supernatant liquid was kept in a separate tube and the pellets were again extracted similarly, twice more. The supernatants were combined and frozen until analysis for soluble fructose, glucose, sucrose, and sorbitol using HPLC - MS (Mehouachi et al., 1995). The residue was then analysed for starch (St) concentration. Starch remaining in the undissolved pellet of plant material after ethanol extractions were enzymatically (amyloglucosidase; Fluka-10115, Sigma-Aldrich, St Louis, MO, USA) reduced to glucose using the method detailed by Palacio et al. (2007). The concentration of starch was determined by a phenol-sulfuric acid colorimetric assay (Dubois et al., 1956) as modified by Buysse and Merckx (1993).

\subsection{Data Analysis}

Data were subjected to Analysis of Variance and/or Linear Regression analysis using Genstat 12.1 (VSN International Ltd). Data are presented as mean values for each treatment. Significance was calculated at $\mathrm{P}=0.05$ 
and least significant difference (LSD) used for comparison of mean values in the tables and figures. No data transformations were necessary.

\section{Results}

\subsection{Crop Yields}

There were significant differences in estimated yield efficiency (Table 1) with level of bud thinning in Van in 2010/11 $\left(\mathrm{F}_{2,74}=46.14, \mathrm{p}<0.001\right)$ and 2011/12 $\left(\mathrm{F}_{2,58}=5.42, \mathrm{p}=0.007\right)$ but timing of thinning was not significant and there were no significant interactions. Reducing bud density showed similar trends in both cultivars in the first season (Trials 1 and 2), with the $1 \mathrm{bud} /$ spur treatment resulting in approximately half the crop load (represented as number of fruit per $\mathrm{cm}^{2}$ LCSA) of the higher thinning level (Figure 1). Natural fruit set in the second season (Trial 3 ) was very low; thinning to 2 buds/spur in this trial reduced crop load to approximately $50 \%$ of the natural set (Figure 1, Table 1).

Table 1. The effect of bud thinning on yield efficiency ( $\mathrm{g}$ fruit per $\mathrm{cm} 2$ tree cross-sectional area (TCSA) for Trial 1 and limb cross-sectional area (LCSA) for Trials 2 and 3) in 'Van' and 'Sweetheart'. Bars represent one standard error of the mean. Note crop load in the Van 2010/11 trial is based on TCSA of 'Van' and 'Sweetheart' cherry varieties on F-12/1 rootstocks and pruned to a KGB system. Means within columns followed by different letters are significantly different as calculated by least significant difference at $\mathrm{P}=0.05$ using Genstat 12.1 (VSN International Ltd)

\begin{tabular}{llll}
\hline & \multicolumn{2}{l}{ Yield efficiency $\left(\mathrm{g} / \mathrm{cm}^{2}\right)$} & \\
& Trial 1: Van & Trial 2: Sweetheart & Trial 3: Van \\
& $(2010 / 11 ;$ TCSA $)$ & $(2010 / 11 ;$ LCSA $)$ & $(2011 / 12 ;$ LCSA $)$ \\
\hline 1 bud/spur & $109 \mathrm{a}$ & $114 \mathrm{a}$ & - \\
2 buds/spur & $149 \mathrm{~b}$ & $170 \mathrm{~b}$ & $79 \mathrm{a}$ \\
4 buds/spur & $222 \mathrm{c}$ & $215 \mathrm{c}$ & $108 \mathrm{ab}$ \\
natural & - & - & $123 \mathrm{~b}$
\end{tabular}

As shown in Table 1, yield efficiency ( $\mathrm{g}$ fruit $/ \mathrm{cm}^{2}$ ) in 'Sweetheart' and 'Van' sweet cherry.

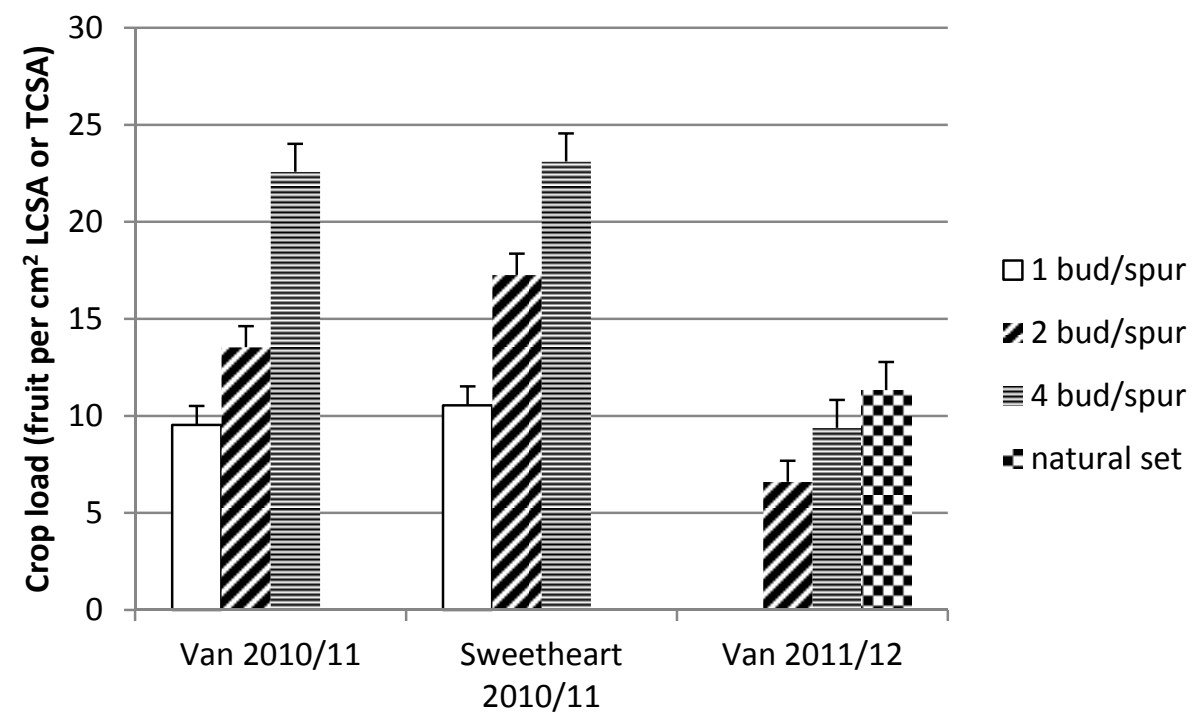

Figure 1. The effect of bud thinning on crop load (number of fruit per $\mathrm{cm}^{2}$ limb cross-sectional area (LCSA)) in 'Van' and 'Sweetheart'. Bars represent one standard error of the mean. Note crop load in the Van 2010/11 trial is based on TCSA 


\subsection{Quality at Harvest}

Fruit diameter, flesh firmness, skin puncture force, TSS, and TA negatively correlated with fruit $/ \mathrm{cm}^{2}$ LCSA in Trials 2 and 3 (Table 2). Similarly, FirmTech and stem pull values negatively correlated with fruit/ $\mathrm{cm}^{2}$ LCSA in Trial 3 (Table 2).

Table 2. Correlations of quality attributes with crop load (number of fruit per $\mathrm{cm}^{2}$ tree cross-sectional area (TCSA) for Trial 1 and limb cross-sectional area (LCSA) for Trials 2 and 3) of 'Van' and 'Sweetheart' cherry varieties on F-12/1 rootstocks and pruned to a KGB system

\begin{tabular}{|c|c|c|c|c|c|c|c|c|c|}
\hline & 'Van' 2010/11 & $r^{2}$ & $\mathrm{p}$ & 'Sweetheart' 2010/11 & $r^{2}$ & $\mathrm{p}$ & 'Van' 2011/12 & $r^{2}$ & $\mathrm{p}$ \\
\hline Fruit diameter $(\mathrm{mm})$ & $=-0.2139 x+31.754$ & 0.83 & 0.0001 & $=-0.0732 x+29.104$ & 0.38 & 0.0067 & $=-0.1029 x+25.964$ & 0.57 & 0.0839 \\
\hline Flesh firmness $\left(\mathrm{kg} / \mathrm{cm}^{2}\right)$ & $=-0.0017 x+0.1231$ & 0.76 & 0.0001 & $=-0.0027 x+0.1647$ & 0.68 & 0.0001 & $=-0.0012 x+0.1061$ & 0.65 & 0.0517 \\
\hline Skin puncture force $\left(\mathrm{kg} / \mathrm{cm}^{2}\right)$ & $=-0.0049 x+0.426$ & 0.68 & 0.0001 & $=-0.007 x+0.4698$ & 0.72 & 0.0001 & $=-0.0034 x+0.4121$ & 0.76 & 0.0236 \\
\hline Firmtech $\left(\mathrm{g} / \mathrm{mm}^{2}\right)$ & - & & & - & & & $=-2.2772 x+337.8$ & 0.84 & 0.0099 \\
\hline TSS $\left({ }^{\circ}\right.$ Brix $)$ & $=-0.1642 x+10.109$ & 0.79 & 0.0001 & $=-0.2114 x+21.335$ & 0.58 & 0.0003 & $=-0.0694 x+19.113$ & 0.15 & 0.4551 \\
\hline $\mathrm{TA}(\mathrm{g} / 100 \mathrm{~g})$ & $=-0.1118 x+11.219$ & 0.75 & 0.0001 & $=-0.0338 x+9.2103$ & 0.16 & 0.1052 & $=-0.0425 x+12.79$ & 0.25 & 0.3117 \\
\hline Stem pull force $(\mathrm{N})$ & - & & & - & & & $=-12.713 x+717.76$ & 0.60 & 0.0700 \\
\hline
\end{tabular}

As shown in Table 2, correlations of quality attributes with fruit load per trunk (Trial 1) and limb (Trials 2 and 3) cross-sectional area $\left(\mathrm{cm}^{2}\right)(\mathrm{x})$.

There was a significant interaction effect of thinning level and timing of thinning $\left(\mathrm{F}_{8,2249}=9.17, \mathrm{p}<0.0001\right)$ on fruit diameter in Trial 1; 'Van' in 2010/11 (Figure 2). However fruit diameter from trees which were thinned to the 1 and 2 buds/spur treatments generally followed similar patterns, whilst diameter was generally lower from the 4 buds/spur treatment at all thinning times. Similarly, there was a significant interaction effect of thinning level and timing of thinning $\left(\mathrm{F}_{10,2249}=12.83, \mathrm{p}<0.0001\right)$ on fruit diameter in Trial 2; 'Sweetheart' in 2010/11 (Figure 2). However in contrast to 'Van', fruit diameter was generally only lowered by the 6 and 8 WAFB in the 4 bud/spur treatment. Different responses to time of thinning between varieties were observed. A general decrease in size was observed in fruit from trees thinned later than FB in 'Van', irrespective of crop load, but no such general decrease was observed in 'Sweetheart'. In Trial 3, thinning time had no effect on fruit diameter (results not presented), but level of crop load had a significant effect $\left(\mathrm{F}_{2,892}=20.53, \mathrm{p}<0.0001\right)$ with larger fruit occurring at the lowest crop load. Fruit size in general was higher in 'Van' in 2011/12 than in 2010/11. Mean fruit weight was inversely related to crop load in Trial 3 (weight $=13.13-0.056 *$ crop load; $R^{2}=0.79$ ). Fruit weight was also positively correlated with fruit diameter (weight $=0.82 \times$ diameter $-12.30, \mathrm{r}^{2}=0.92$ ). There were no effects of crop load or timing of thinning on fruit colour (results not shown). 


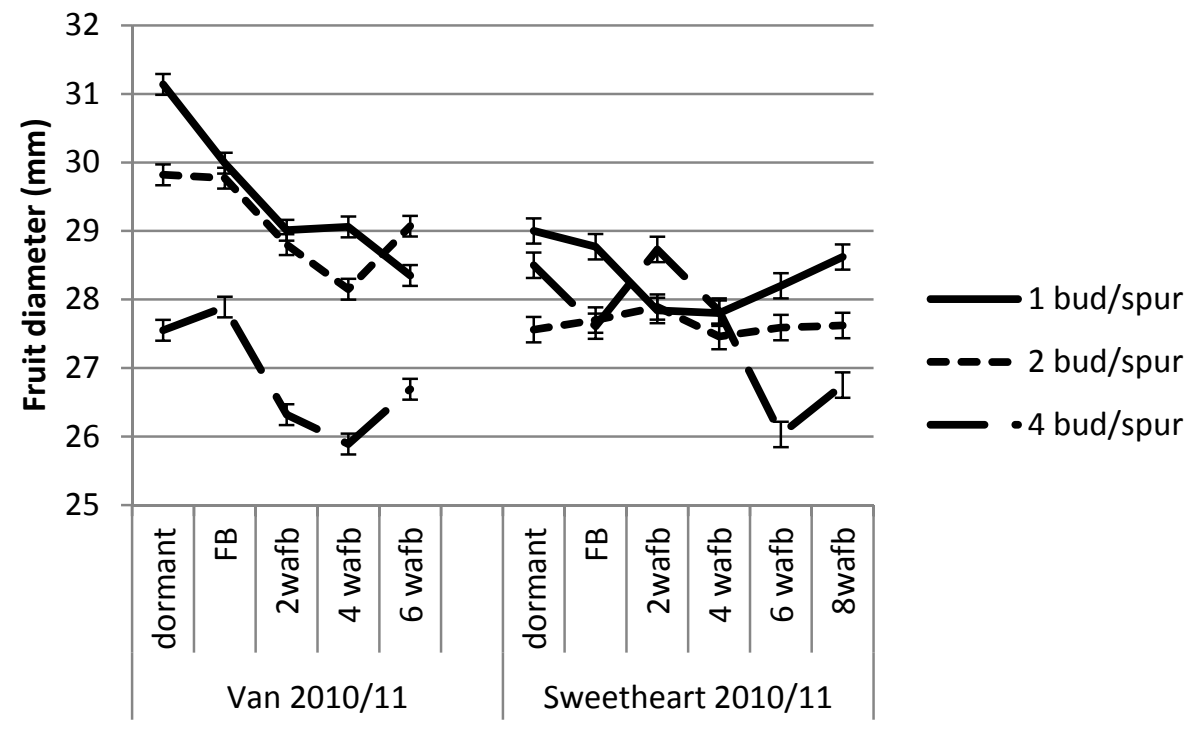

Figure 2. The effect of time and level of bud thinning on fruit diameter of 'Van' and 'Sweetheart' cherry (Trials 1 and $2-2010 / 11)$. Bars represent one standard error of the mean

There was a significant interaction of crop load and timing of thinning on fruit flesh firmness in Trial 1 ('Van' in $\left.2010 / 11 ; \mathrm{F}_{2,2249}=6.66, \mathrm{p}<0.001\right)$. Fruit flesh firmness generally increased as crop load decreased but this trend was far less marked in Trial 3 ('Van' in 2011/12; crop load treatment; $F_{2,899}=6.91, \mathrm{p}<0.001$ ) (Figure 3a). There was a significant interaction of crop load and timing of thinning on fruit flesh firmness in Trial 2 ('Sweetheart' in $2010 / 11 ; \mathrm{F}_{10,2249}=10.31, \mathrm{p}<0.001$ ), although in contrast to 'Van' in 2010/11 fruit flesh firmness was considerably elevated in the $1 \mathrm{bud} /$ spur treatment compared with other crop load treatments (Figure 3b).

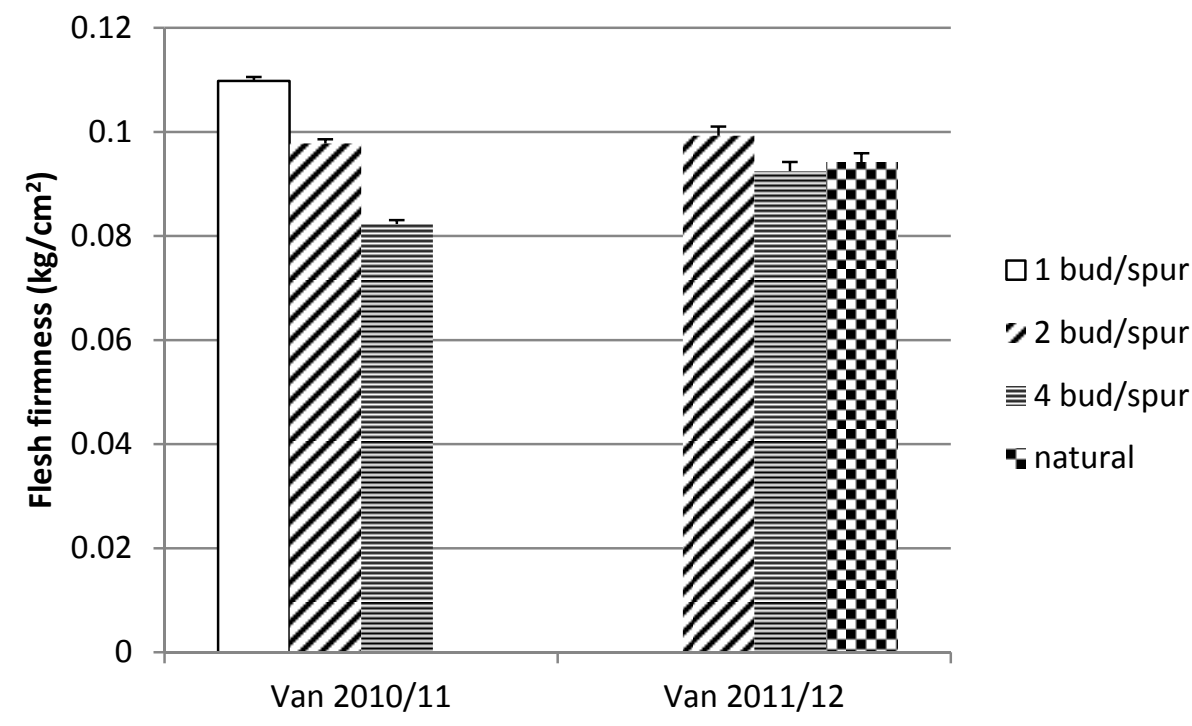

Figure 3a. The effect of bud thinning on fruit firmness of 'Van' cherry (Trials 1 and 3). Bars represent one standard error of the mean 


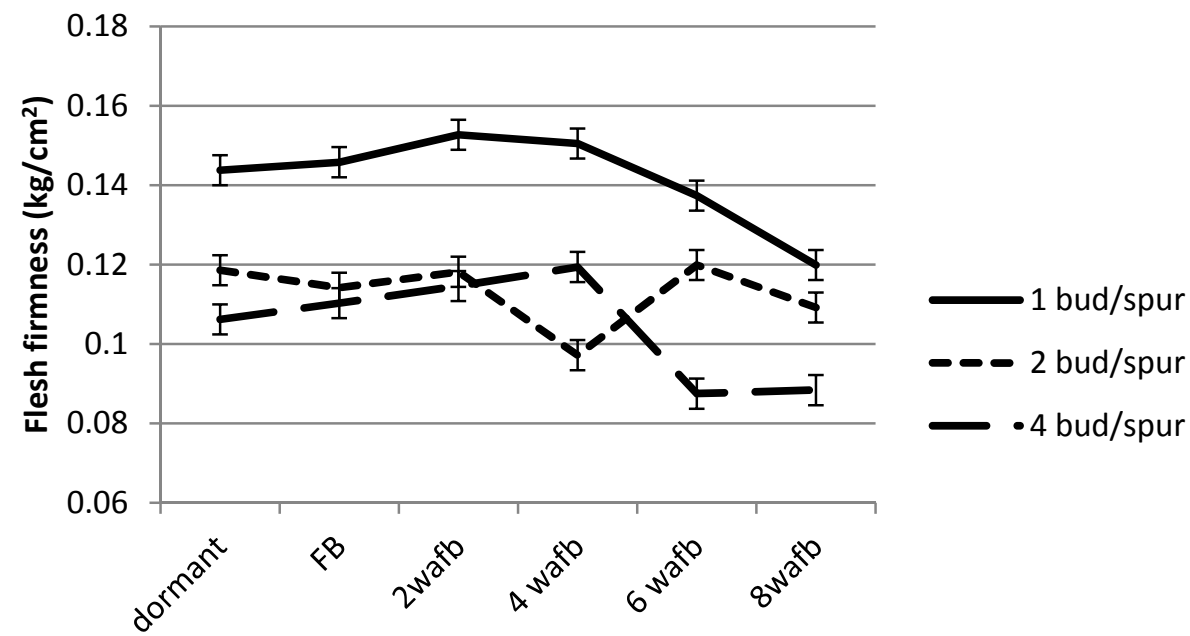

Sweetheart 2010/11

Figure 3b. The effect of time and level of bud thinning on fruit flesh firmness of 'Sweetheart' cherry (Trial 2). Bars represent one standard error of the mean

There were significant interaction effects for crop load and timing of thinning on soluble solids and TA in Trials 1 $\left(\mathrm{F}_{8,269}=4.13, \mathrm{p}=<0.001\right.$ and $\mathrm{F}_{8,269}=4.69, \mathrm{p}=<0.001$, respectively $)$ and $2\left(\mathrm{~F}_{10,269}=6.13, \mathrm{p}=<0.001\right.$ and $\mathrm{F}_{10,269}=4.66$, $\mathrm{p}=<0.001$, respectively). The results showed similar general trends as flesh firmness in both varieties (Figures $4 \mathrm{a}$, b, 5a, b). In Trial 3 we found no interaction and a significant effect of crop load only on soluble solids $\left(\mathrm{F}_{2,59}=3.48\right.$, $\mathrm{p}=0.039$ ) and no effects on TA.

There was significant effect of crop load (but no effect of timing of thinning) on percent fruit cracking in Van in 2010/11 $\left(\mathrm{F}_{2,74}=51.20, \mathrm{p}=<0.001\right.$; Figure 6$)$ but not in 2011/12. There was a significant effect of crop load on cracking in Sweetheart in 2010/11 also, but this was part of another study that has been published elsewhere (Measham et al.,2012).

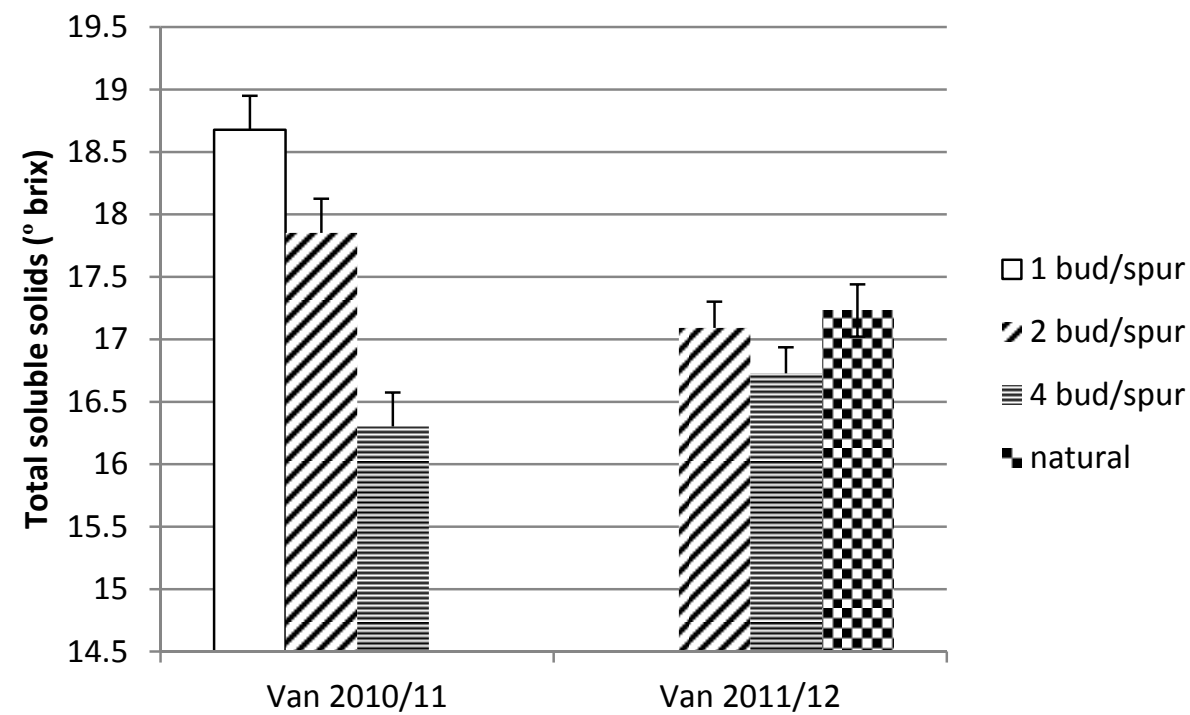

Figure 4a. the effect of bud thinning on sugar content of 'Van' cherry fruit (Trials 1 and 3). Bars represent one standard error of the mean 


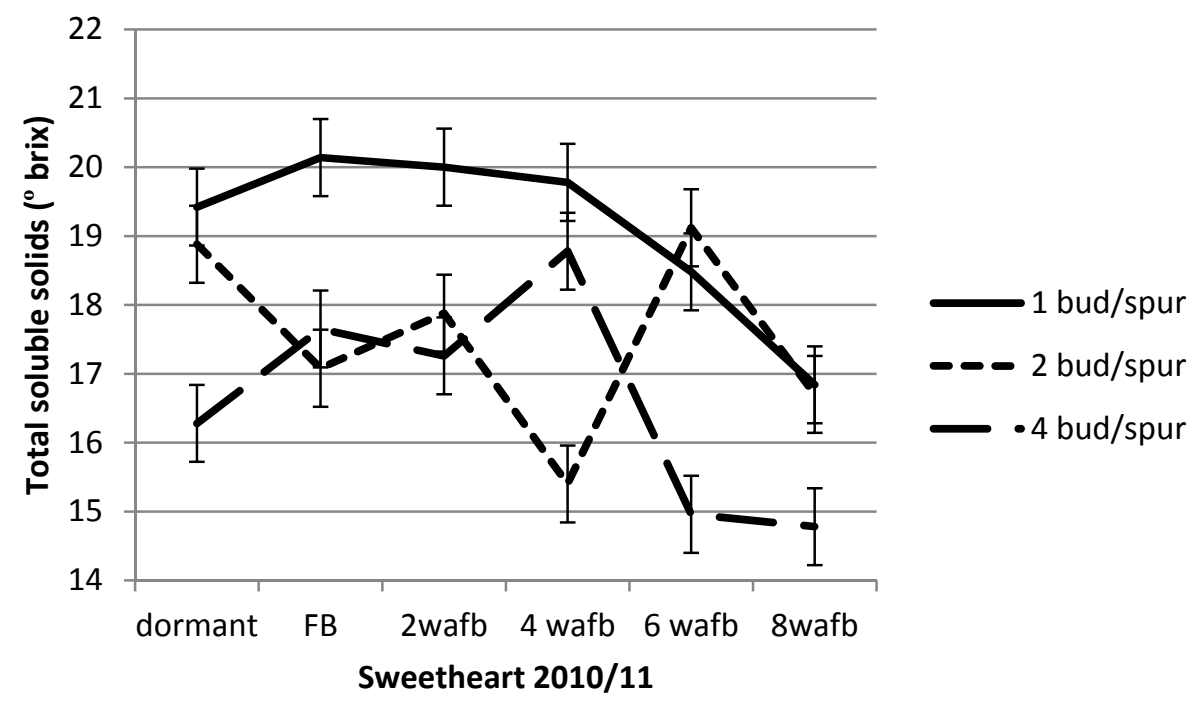

Figure 4b. the effect of time and level of bud thinning on sugar content of 'Sweetheart' cherry fruit (Trial 2). Bars represent one standard error of the mean

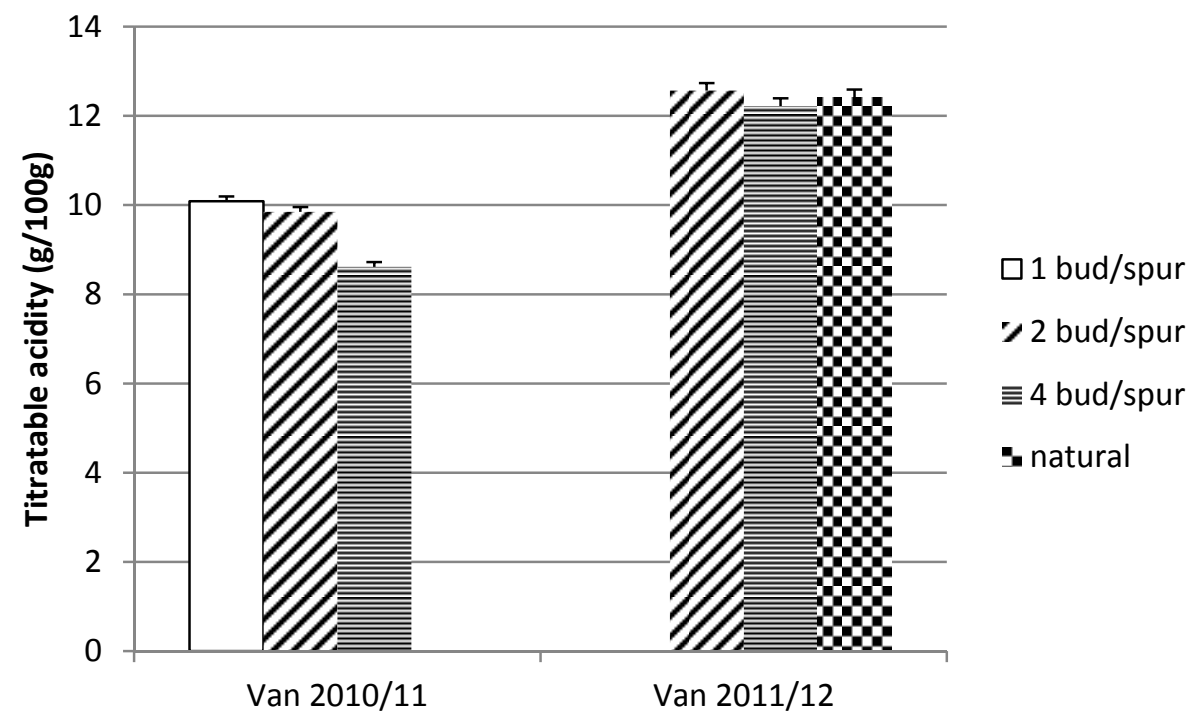

Figure 5a. the effect of bud thinning on titratable acidity of 'Van'cherry fruit (Trials 1 and 3). Bars represent one standard error of the mean 


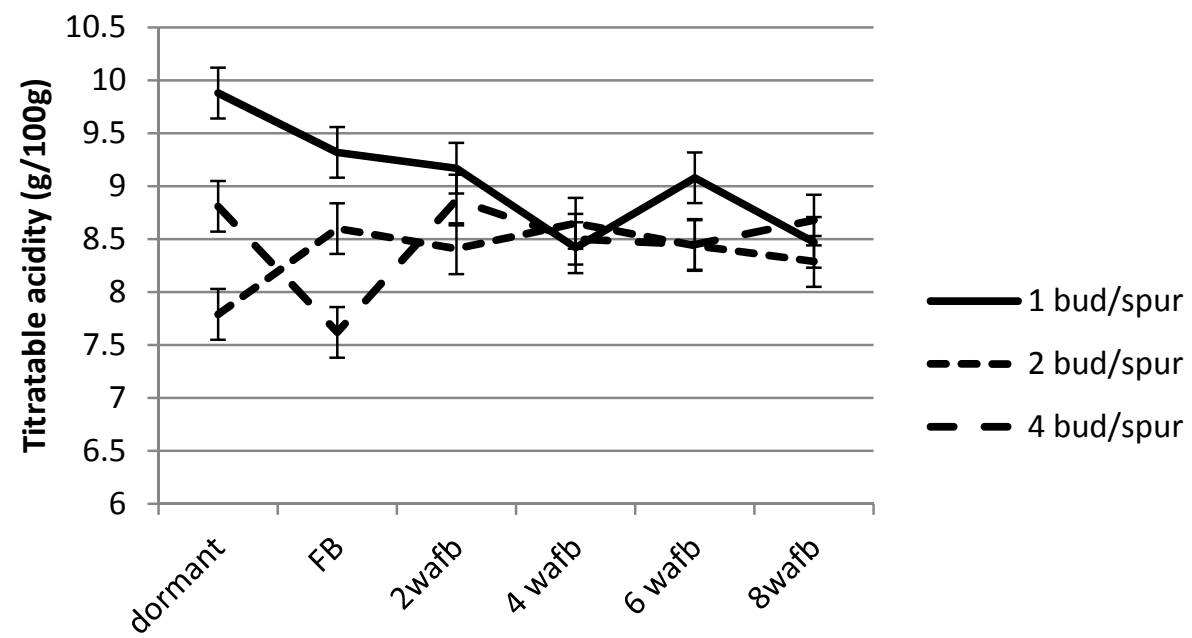

Sweetheart 2010/11

Figure 5b. the effect of time and level of bud thinning on titratable acidity of 'Sweetheart' cherry fruit (Trial 2).

Bars represent one standard error of the mean

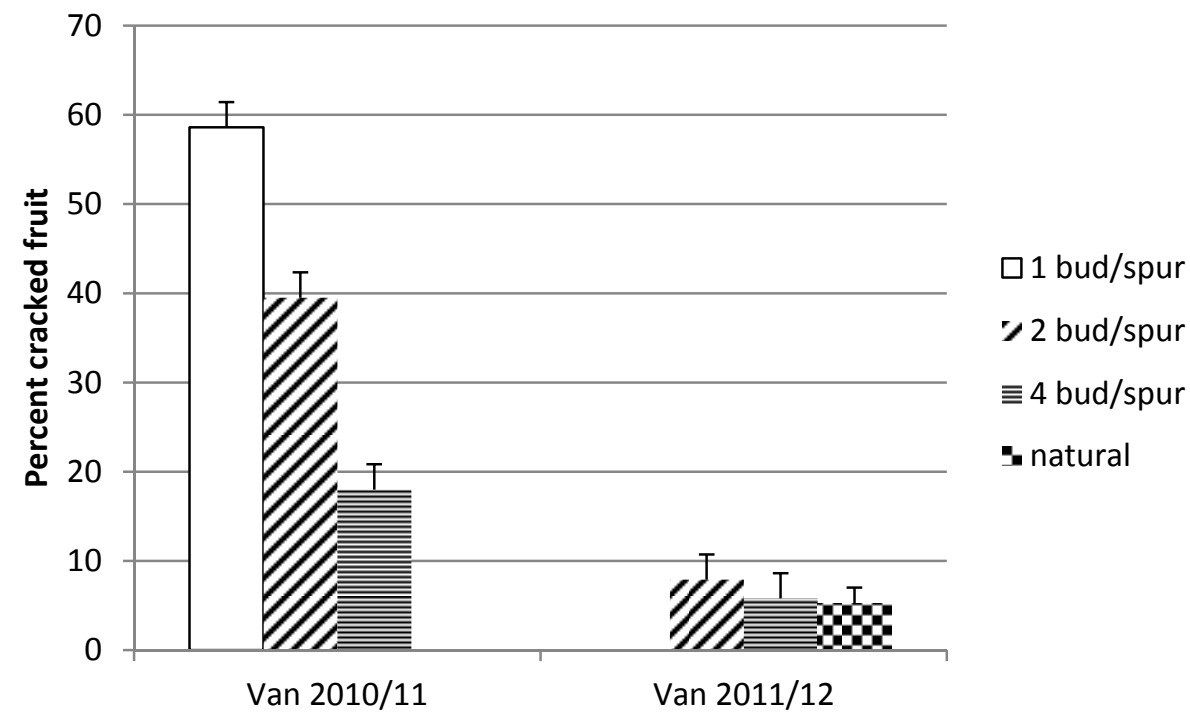

Figure 6. The effect of bud thinning on percent cracked fruit of 'Van' cherry fruit (Trials 1 and 3). Bars represent one standard error of the mean

\subsection{Quality Post-Harvest}

Fruit had significantly higher flesh firmness and skin puncture values 28 days post-harvest relative to fruit at harvest (Figure 7). Weight and TA significantly decreased whilst colour and TSS significantly increased during storage (Figure 8). Flesh firmness (flesh firmness $=0.0004 *$ firmtech $-0.04, \mathrm{r}^{2}=0.92$ ) and skin puncture (skin puncture $=0.0011 *$ firmtech $+0.03, \mathrm{r}^{2}=0.93$ ) correlated with FirmTech values, irrespective of assessment at harvest or post-harvest. 


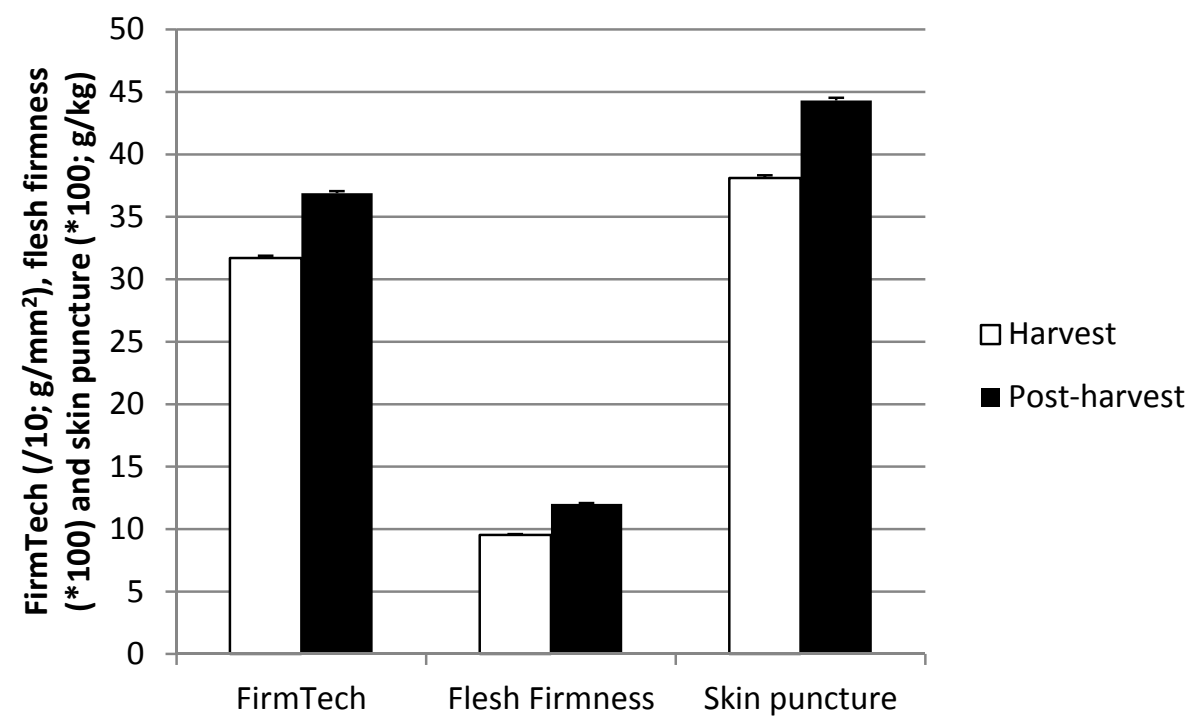

Figure 7. Differences in fruit firmness (FirmTech), flesh firmness and skin puncture force in 'Van' fruit at harvest and 28 days post-harvest (Trial 3). Bars represent one standard error of the mean

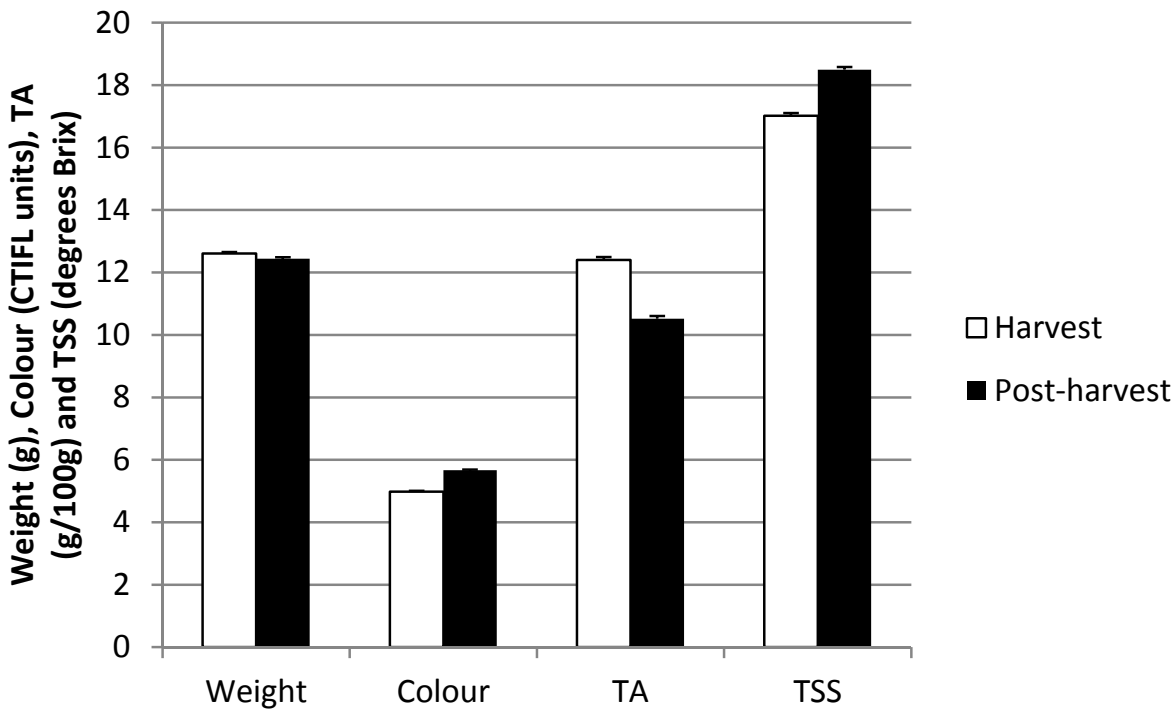

Figure 8. Differences in fruit weight, skin colour, titratable acidity (TA) and total soluble solids (TSS) in 'Van' fruit at harvest and 28 days post-harvest (Trial 3). Bars represent one standard error of the mean

\subsection{Crop Load and Carbohydrates}

'Sweetheart' trees thinned at dormancy contained significantly greater soluble solids and starch at two weeks postharvest in leaves, stem, trunk and roots than trees thinned 8 WAFB (Figure 9). Trees thinned while dormant had double the TSS in leaves compared to roots, while branch and stem levels were approximately half that of roots. A different pattern was seen in the late-thinned trees, with leaf and roots having similar sugar levels. 

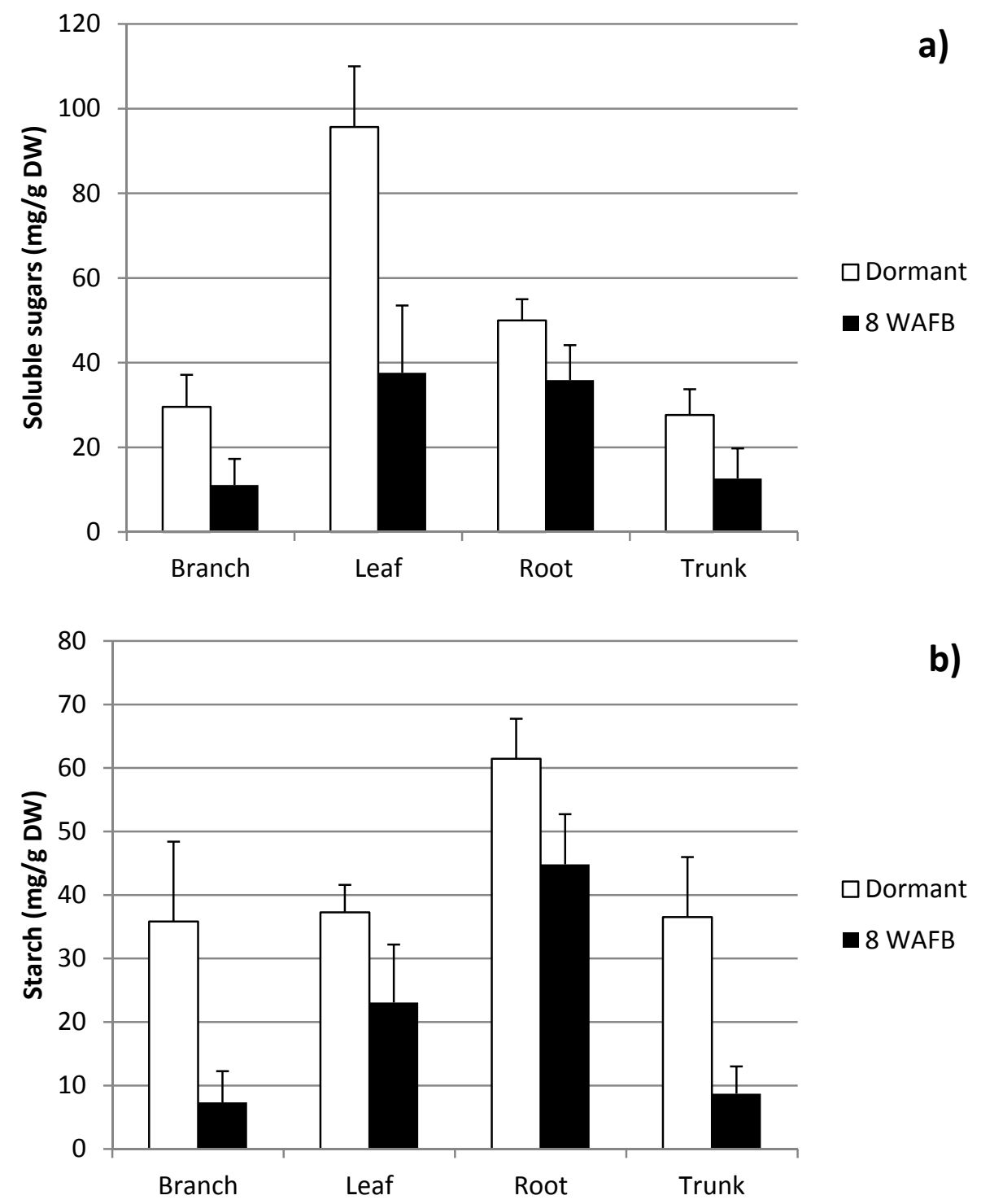

b)

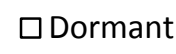

8 WAFB

Figure 9. Effect of thinning buds at dormancy (Dormant) and 8 weeks after full bloom (8 WAFB) on 'Sweetheart' tree branch, leaf, root and trunk TSS (a) and starch (b) levels sampled 14 days post-harvest (Trial 2). Bars represent one standard error of the mean

\subsection{Correlation of Firmness Values from GÜSS Fruit Texture Analyser and Firmtech II}

A correlation of fruit flesh puncture values with fruit compression test values yielded a liner relationship (Figure $\left.10 ; \mathrm{y}=0.0004 \mathrm{x}-0.0416, \mathrm{R}^{2}=0.92442, \mathrm{p}<0.0001\right)$. 


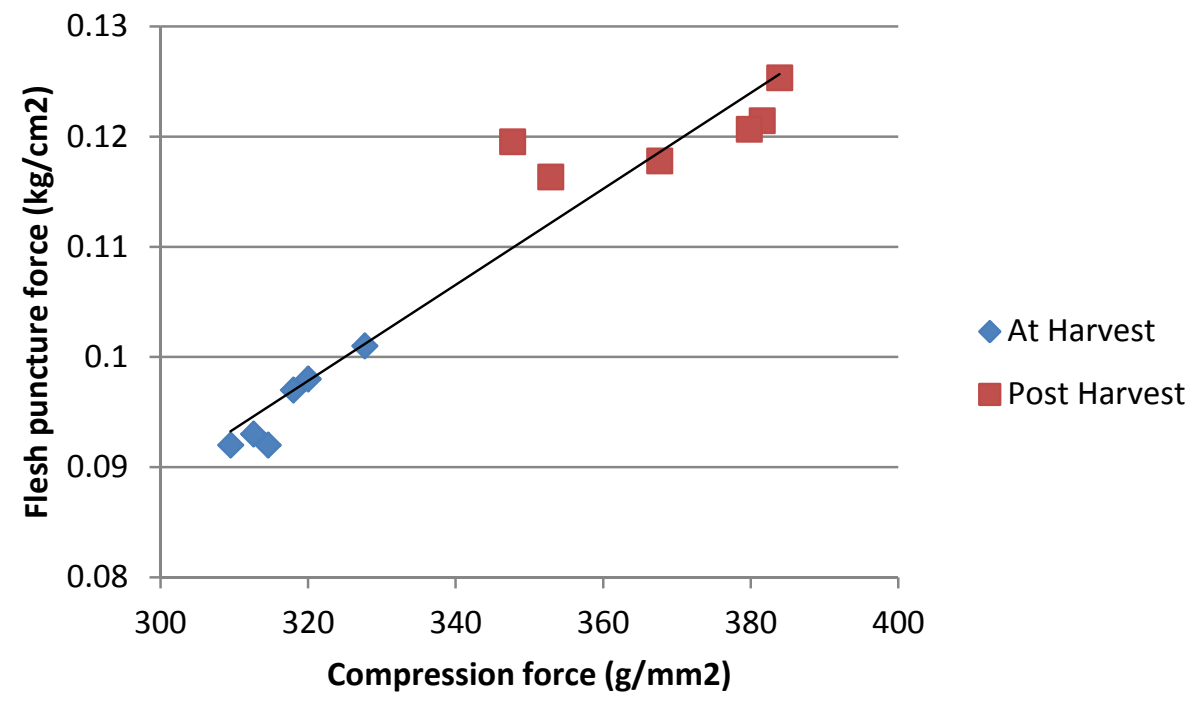

Figure 10. Flesh puncture force (measured with the GÜSS Fruit Texture Analyser) correlated against whole fruit compression force (measured with the Firmtech II) of fruit at harvest (Diamond symbols) and 28 days post-harvest

(Square symbols). Each symbol represents an average of five replicates, each comprising 15 fruit from two branches. Each symbol was from separate treatments of thinned to 2 or 4 buds per spur or left with the natural crop load at pre-bloom or 6 weeks after full bloom, i.e. three thinning treatments $\mathrm{x} 2$ thinning times $=6$ treatments.

$$
y=0.0004 x-0.0416, R^{2}=0.9244, p<0.0001
$$

\section{Discussion}

This study reveals significant interaction between crop load and the time of thinning on sweet cherry fruit quality. High crop loads resulted in significant reductions to fruit size in 'Sweetheart' when thinned several weeks after flowering (i.e., 6 and 8 WAFB), but there was no loss of size with earlier thinning. Further, these late thinning times resulted in significant decreases in firmness and TSS under higher crop loads in 'Sweetheart'. The reductions in TA of fruit from trees thinned after FB were not observed in fruit from trees thinned earlier. These findings are consistent with earlier reports that supply of carbohydrates and nutrient resources is limited under high crop load (Proebsting \& Mills 1981). This may be particularly so for 'Sweetheart' trees trained to the KGB system and thinned after full bloom, presumably due to greater investment of carbohydrate resources in fruitlets that were subsequently thinned. This suggestion is supported by our data on tree carbohydrate reserves that reveal significantly lower levels in limbs thinned 8 WAFB compared with those thinned while dormant. However, replication of the impacts seen in this study on 'Sweetheart' would be required to show that they are consistent. The results for 'Van' in 2010/11 were in contrast to the results found in 'Sweetheart'. Studies by Einhorn et al. (2011) and Measham et al. (2012) have shown that manipulation of crop load has had inconsistent results over different seasons. A general decline in fruit size was observed with time of thinning from FB irrespective of crop load treatment and no effects of timing of thinning on firmness, TSS or TA were observed in Van in 2010/11. The reasons for the difference in response between varieties in 2010/11 can be speculated to be variety or age-related differences, although crop load differences can be eliminated as the treatments arrived at virtually identical crop loads between the varieties.

The results of this study may imply a distinct carbohydrate source:sink relationship in 'Sweetheart' relative to 'Van', where carbohydrate source is limiting potential fruit size and earlier thinning results in quality benefits such as increased size - perhaps due to greater resource availability for cell division given that cell division is complete within 10 days of full bloom (Tukey \& Young 1939) and that no similar decline was seen in firmness, TSS or TA. That potential fruit size is set early in the fruit development ontogeny is tacitly supported by the lack of considerable difference in size between the 1 and 2 bud/spur treatments in either variety whilst firmness was significantly higher in the 1 than the 2 bud/spur treatments in both varieties in one season. This is additionally supported by an earlier study (Measham et al., 2012) that suggested pre-bloom thinning would be more effective for manipulating size whilst minimizing the risk of fruit cracking through water uptake during cell expansion in the later stages of fruit growth. 
This study observed distinct impacts of crop load manipulation in 'Van' over two seasons. The impacts of crop load on fruit quality were only significant in the first season, when the natural crop load was generally higher than the second season. This is consistent with other studies that suggest crop load manipulation as a means to improve fruit quality is neither consistent, nor necessary, unless a high natural crop load occurs (Neilsen et al., 2007, Einhorn et al., 20011; Measham et al., 2012). It should be noted that crop loads in all trials in this study range from medium to light according to the criteria set by Neilsen et al. (2007), however these values were set for fruit grown on 'Gisela 5' rootstock which is precocious compared to F-12/1 (Robinson and Hoying in press). These authors suggest that $400 \mathrm{~g}$ fruit $/ \mathrm{cm}^{2}$ trunk cross-sectional area (or approx. $45 \mathrm{fruit} / \mathrm{cm}^{2}$ TCSA) represents a high crop load for Lapins, while $100 \mathrm{~g}$ fruit $/ \mathrm{cm}^{2}$ trunk cross-sectional (or approx. 10 fruit $/ \mathrm{cm}^{2}$ TCSA) area is a high load for 'Bing, and that high crop load thresholds therefore vary with variety. Measham et al. (2012) did not find a fruit size diminishing effect in trees grown on Mazzard until a threshold of 25 fruit $/ \mathrm{cm}^{2}$ TCSA was achieved, and that the risk of cracking increased below a threshold of $10 \mathrm{fruit} / \mathrm{cm}^{2}$ TCSA in several varieties. Moreover, in manipulated crop load trials (Measham et al. in press) and in a survey of natural crop load (Measham et al. 2012) of varieties grown in Southern Tasmania, loads rarely exceed 15 fruit $/ \mathrm{cm}^{2}$ TCSA. Regulating crop load for optimum size therefore, relies on the knowledge of crop load thresholds at which size diminishes for each variety/rootstock combination. In these previous studies and in the second year of this current study, the levels may not have reached that threshold.

Negative correlations of all quality parameters, except colour, were found with increasing crop load. This emphasizes the need for effective crop load monitoring, with regulation as needed, particularly where high quality of fruit is necessary for successful export. Whilst most quality measure, comparisons within the 2010/11 season were similar for a given crop load and time of thinning, flesh firmness was higher for a given crop load in 'Sweetheart' than 'Van'. Olmstead et al. (2007) reported differences between cultivars in fruit mesocarp cell numbers, hence the difference in firmness observed between 'Sweetheart' and 'Van' fruit in this study may be attributable to differences in cell numbers between the two cultivars. The two varieties also have different ripening periods such that cell expansion and water content could be a contributing factor.

Strong correlations were found between firmness measured with a FirmTech compression test and either a skin or flesh penetration test measured with a Güss texture analyser, irrespective of whether fruit was measured at harvest or 28 days post-harvest. This is despite the skin puncture measure including force required to puncture relatively 'elastic' skin that may not reflect flesh firmness (Looney \& Webster 1996). These correlations suggest that for practical purposes, measurement of firmness with the relatively quick Firmtech can replace either flesh firmness or skin puncture force penetrometer measurements. Additionally, results can be easily assimilated by industry stakeholders as it is a widely used tool in processing houses.

Post-harvest fruit quality assessments of 'Van' fruit showed an increase in all measures of firmness due to dehydration, consistent with the decrease in fruit weight (Drake \& Elfving, 2002; Alique et al., 2006; Puniran et al., 2012). Whilst crop load affected sugars and TA at harvest, treatments responded similarly post-harvest, emphasizing the importance of initial quality to the consumer experience post-harvest. This is consistent with the conclusion of Kupferman (1986) that the best time to harvest is at Mahogony stage when firmness, weight and TSS are highest. However, according to Drake and Elfving (2002), while skin colour has long been accepted as the best indicator for the appropriate harvest maturity, loss of quality after storage for 14 days or more is higher for fruit harvested at normal commercial time or later compared with harvesting up to 5 days earlier. Hence there is a risk in harvesting too mature and allowing acidity to drop which has significant implications for flavour perception.

\section{Conclusion}

The bud thinning technique employed resulted in a wide spread of crop loads, and is therefore superior to the use of ATS sprays (eg. Schoedl et al., 2009) for the purpose of investigating fruit quality and carbohydrate storage responses to crop load regulation, particularly as all chemical thinning agents can impact negatively on fruit quality (Bound, 2001).

This study showed that crop load and timing of thinning interact - particularly for fruit produced using the KGB system. Results indicated that internal carbohydrate reserves were significantly depleted in late-thinned limbs, although it must be cautioned that these were only investigated in one season. Generally, sweet cherry fruit quality (size, firmness, sugar, acid and stem retention) was optimised through attaining crop load of approximately 10 fruit per $\mathrm{cm}^{2}$ limb cross-sectional area through thinning at dormancy or full bloom in this study, although it must be cautioned that poor cracking outcomes have been observed when thinned at full bloom (Measham et al., 2012). It is worth noting though that desired crop loads that optimise fruit quality at harvest can only be achieved by thinning if natural load is high, but that diameter increases of $2-3 \mathrm{~mm}$ in response to thinning can increase fruit value by 
$\$ 2-3 / \mathrm{kg}$ if it results in 'up-sizing' to $28 \mathrm{~mm}+$ or $30 \mathrm{~mm}+$ size categories (Reid Pers. Comm. May 2013). Additionally, achieving quality from low loads must be balanced with the risk of increased cracking (Measham et al., 2012) and in some cases reduced yields (Einhorn et al., 2011) or very large soft fruit (Neilsen et al., 2007). The development of a 'user-friendly' guide for growers to assess fruit set and subsequent crop load quickly would be beneficial in decision making processes around thinning for optimal fruit quality.

The similar rates of deterioration in post-harvest quality regardless of crop load or timing of thinning per se, emphasises the importance of fruit quality at-harvest to ensure post-harvest quality of exported fruit for the consumer. This study exposes the interactive effects of the level and timing of crop-load regulation on cherry fruit quality. Alternative growing systems may result in more effective light capture and therefore enable the production of higher yields, without a cost to quality, than that currently achieved under the KGB system.

\section{Acknowledgements}

The project has been funded by Horticulture Australia Ltd using the cherry industry levy, voluntary contributions from Washington Tree Fruit Research Commission and matched funds from the Australian Government. DC Close received a University of Tasmania Rising Stars Grant. We thank Nic Hansen, Howard Hansen and Tim Reid for generous access to orchards and donations of fruit.

\section{References}

Alique, R., Martinez, M. A., \& Alonso, J. (2006). Metabolic response to two hydrocooling temperatures in sweet cherries cv. Lapins and cv. Sunburst. Journal of the Science of Food and Agriculture, 86, 1847-1854. http://dx.doi.org/10.1002/jsfa.2516

Ayala, M., \& Andrade, M. P. (2009) Effects of fruiting spur thinning on fruit quality and vegetative growth of sweet cherry (Prunus avium). Ciencia E Investigacion Agraria, 36, 443-450.

Bound, S. A. (2001). Managing crop load. In R. Dris, R. Niskanen, \& M. Jain (Eds.), Crop management and postharvest handling of horticultural products (Vol 1: Quality Management.). Oxford \& IBH Publishing Co Pvt. Ltd, New Delhi, India. http://dx.doi.org/10.1071/EA03161

Bound, S. A., \& Jones, K. M. (2004). Ammonium thiosulphate as a blossom thinner of 'Delicious' apple, Winter Cole pear and Hunter' apricot. Australian Journal of Experimental Agriculture, 44, 931-937.

Buysse, J., \& Merckx, R. (1993) An improved colorimetric method to quantify sugar content of plant tissue. Journal of Experimental Botany, 44, 1627-1629. http://dx.doi.org/10.1093/jxb/44.10.1627

Close, D. C., Jotic, P., Oakford, M., \& Whiting, M. D. (in press). Traning system and tree density affect cost:benefit but have little impact, relative to season, on fruit yield and quality of 'Lapins' In Tasmania, Australia. Acta Horticulturae.

Childers, N. F. (1983). Modern fruit science. Florida, Gainesville, Horticultural Publications.

Drake, S. R., \& Elfving, D. C. (2002). Indicators of maturity and storage quality of 'Lapins' sweet cherry. HortTechnology, 12, 687-690.

Dubois, M., Gilles, K. A., Hamilton, J. K., Rebers, P. A., \& Smith, F. (1956) Colorimetric method for determination of sugars and related substances. Anals of Chemistry, 28, 350-356. http://dx.doi.org/10.1021/ac60111a017

Einhorn, T. C., Laraway, D., \& Turner, J. (2011). Crop load management does not consistently improve crop value of 'Sweetheart'/'Mazzard' sweet cherry trees. HortTechnology, 21, 546-553.

Green, K. (2005). High density cherry systems in Australia. Acta Horticulturae, 667, 319-324.

Kupferman, E. (1986). An introduction to cherry quality and handling. Post-Harvest Pomology Newsletter, 3-8.

Link, H. (2000). Significance of flower and fruit thinning on fruit quality. Plant Growth Regulation, 31, 17-26. http://dx.doi.org/10.1023/A:1006334110068

Looney, N. E., \& Webster, A. D. (1996). Cherries: Crop Physiology Production and Uses. Cambridge: University Press.

Measham, P. F., Gracie, A. J., Bound, S. A., \& Wilson, S. J. (in press). An alternative view on rain-induced cracking of sweet cherries (Prunus avium L). Proceedings Sixth International Cherry Symposium, Spain 2009.

Measham, P. F., Bound, S. A., Gracie, A. J., \& Wilson, S. J. (2012). Crop load manipulation and fruit cracking in sweet cherry (Prunus avium L.). Advances in Horticultural Science, 26, 25-31. 
Mehouachi, J., Serna, D., Zaragoza, S., Agusti, M., Talon, M., \& Primo-Millo, E. (1995). Defoliation increases fruit abscission and reduces carbohydrate levels in developing fruits and woody tissues of Citrus unshiu. Plant Science, 107, 189-197. http://dx.doi.org/10.1016/0168-9452(95)04111-7

Neilsen, G., Kappel, F., \& Neilsen, D. (2007). Fertigation and crop load affect yield, nutrition, and fruit quality of 'Lapins' sweet cherry on Gisela 5 rootstock. HortScience, 42, 1456-1462.

Olmstead, J. W., Iezzoni, A. F., \& Whiting, M. (2007). Genotypic Differences in Sweet Cherry Fruit Size are Primarily a Function of Cell Number. Journal of the American Society of Horticultural Science, 132, 697-703.

Palacio, S., Maestro, M., \& Montserrat-Martí, G. (2007). Seasonal dynamics of non-structural carbohydrates in two species of mediterranean sub-shrubs with different leaf phenology. Environmental and Experimental Botany, 59, 34-42. http://dx.doi.org/10.1016/j.envexpbot.2005.10.003

Puniran, N., Close, D. C., Bound, S. A., Corkrey, R., \& Whiting, M. D. (2012). Fruit colour, size and temperature affect the shelf life of sweet cherry. Acta Horticulturae, 934, 995-1001.

Proebsting, E. L., \& Mills, H. H. (1981). Effects of season and crop load on maturity characteristics of Bing cherry. Journal of the American Society of Horticultural Science, 106, 144-146.

Robinson, T., \& Hoying, S. A. (in press). Training system and rootstock effect yield, fruit size, fruit quality and crop value of sweet cherry. Proceedings Sixth International Cherry Symposium, Spain 2009.

Schoedl, K., Denk, A., Hummelbrunner, S., Modl, P., \& Forneck, A. (2009). No improvement in fruit quality through chemical flower thinning in sweet cherr (prunus avium L.). Journal of the Science of Food and Agriculture, 89, 1236-12040. http://dx.doi.org/10.1002/jsfa.3581

Tukey, H. B., \& Young, J. O. (1939). Histological study of the developing fruit of the sour cherry. Botanical Gazette, 100, 723-749. http://dx.doi.org/10.1086/334827

von Bennewitz, E., Sanhueza, S., \& Elorriaga, A. (2010). Effect of different crop load management strategies on fruit production and quality of sweet cherries (Prunus avium L.) 'Lapins'in central Chile. Journal of Fruit and Ornamental Plant Research, 18, 51-57.

Whiting, M. D., Ophardt, D., \& McFerson, J. R. (2006). Chemical blossom thinners vary in their effect on sweet cherry fruit set, yield, fruit quality and crop value. HortTechnology, 16, 66-70.

Whiting, M. D., \& Lang, G. A. (2004). 'Bing'sweet cherry on the dwarfing rootstock 'Gisela 5': Thinning affects fruit quality and vegetative growth but not net $\mathrm{CO}_{2}$ exchange. Journal of the American Society of Horticultural Science, 129, 407-415.

\section{Copyrights}

Copyright for this article is retained by the author(s), with first publication rights granted to the journal.

This is an open-access article distributed under the terms and conditions of the Creative Commons Attribution license (http://creativecommons.org/licenses/by/3.0/). 